OPEN ACCESS

Edited by:

Michael Banissy,

Goldsmiths, University of London,

United Kingdom

Reviewed by:

Fiorenzo Laghi,

Sapienza University of Rome, Italy

Varun Dutt,

Indian Institute of Technology Mandi,

India

*Correspondence:

Mayte Navarro-Gil

maytenavarrogil@gmail.com

Specialty section:

This article was submitted to

Cognitive Science,

a section of the journal

Frontiers in Psychology

Received: 30 July 2018 Accepted: 26 March 2019

Published: 11 April 2019

Citation:

Campos D, Modrego-Alarcón M,

López-del-Hoyo Y,

González-Panzano M, Van Gordon W,

Shonin E, Navarro-Gil M and

García-Campayo J (2019) Exploring

the Role of Meditation

and Dispositional Mindfulness on

Social Cognition Domains:

A Controlled Study.

Front. Psychol. 10:809.

doi: 10.3389/fpsyg.2019.00809

\section{Exploring the Role of Meditation and Dispositional Mindfulness on Social Cognition Domains: A Controlled Study}

\author{
Daniel Campos 1,2, Marta Modrego-Alarcón'2,3,4, Yolanda López-del-Hoyo 2,3,4, \\ Manuel González-Panzano ${ }^{3}$, William Van Gordon ${ }^{5}$, Edo Shonin 6 , Mayte Navarro-Gil2,3* \\ and Javier García-Campayo 2,3,4,7
}

\begin{abstract}
1 Laboratorio de Psicología y Tecnología, Department of Basic Psychology, Universitat Jaume I, Castelló de La Plana, Spain, ${ }^{2}$ Instituto de Investigación Sanitaria de Aragón, IIS Aragón, Zaragoza, Spain, ${ }^{3}$ Department of Medicine, Psychiatry and Dermatology, University of Zaragoza, Zaragoza, Spain, ${ }^{4}$ Primary Care Prevention and Health Promotion Research Network, Madrid, Spain, ${ }^{5}$ Human Sciences Research Centre, University of Derby, Derby, United Kingdom, ${ }^{6}$ Awake to Wisdom Centre for Meditation and Mindfulness Research, Ragusa, Italy, ${ }^{7}$ University Hospital Miguel Servet, Zaragoza, Spain
\end{abstract}

Research suggests that mindfulness can induce changes in the social domain, such as enhancing emotional connection to others, prosocial behavior, and empathy. However, despite growing interest in mindfulness in social psychology, very little is known about the effects of mindfulness on social cognition. Consequently, the aim of this study was to explore the relationship between mindfulness and social cognition by comparing meditators with non-meditators on several social cognition measures. A total of 60 participants (meditators, $n=30$; non-meditators, $n=30$ ) were matched on sex, age, and ethnic group, and then asked to complete the following assessment measures: Mindful Awareness Attention Scale (MAAS), Five Facet Mindfulness Questionnaire Short Form (FFMQ-SF), Interpersonal Reactivity Index (IRI), Revised Eyes Test, Hinting Task, Ambiguous Intentions and Hostility Questionnaire (AlHQ), Hospital Anxiety and Depression Scale (HADS), and Screening for Cognitive Impairment in Psychiatry (SCIP). The results showed that meditators reported higher empathy (except for the personal distress subscale), higher emotional recognition, higher theory of mind (ToM), and lower hostile attributional style/bias. The findings also demonstrated that dispositional mindfulness (both total score assessed with MAAS and mindfulness facets using the FFMQ) was associated with social cognition, although it was not equally correlated with all social cognition outcomes, and correlation patterns differ when analyses were conducted separately for meditators and non-meditators. In addition, results showed potential predictors for each social cognition variable, highlighting non-reactivity to inner experience as a key component of mindfulness in order to explain social cognition performance. In summary, the findings indicated that the meditator sample performed better on certain qualities (i.e., empathy, emotional recognition, ToM, hostile attributional style/bias) in comparison to non-meditators and, furthermore, support the notion that mindfulness is related to social cognition, which may have implications for the design of mindfulness-based approaches for use in clinical and non-clinical settings.

Keywords: mindfulness, meditation, social cognition, empathy, emotional recognition, theory of mind 


\section{INTRODUCTION}

Research into mindfulness has increased over the last decade and, consequently, several interventions to promote mindfulness skills have been implemented and widely used in clinical settings (Khoury et al., 2013; Demarzo et al., 2015; Van Gordon et al., 2017). Mindfulness has been conceptualized by Western culture in several ways, and reference is currently made to dispositional (or trait) mindfulness, state mindfulness, and to the actual techniques of mindfulness training (e.g., mindfulness meditation) (Grossenbacher and Quaglia, 2017). Formal meditation, understood as psychological or mind training, has shown to be useful to enhance both dispositional and state mindfulness (e.g., Baer, 2003; Baer et al., 2008, 2012; Kiken et al., 2015), although mindfulness can also be trained through informal practice, such as mindfulness in daily life activities (Salmon et al., 1998; Carmody and Baer, 2008). There is a growing body of evidence highlighting the benefits of mindfulness on health, well-being, attention, cognitive functioning, and cognitive flexibility (e.g., Moore and Malinowski, 2009; Van Gordon et al., 2014; Khoury et al., 2015; Campos et al., 2016; Mira et al., 2016; Raffone and Srinivasan, 2017). Furthermore, mindfulness training has been used to elicit changes in self-awareness, emotion regulation, and neurophysiology (e.g., Ospina et al., 2007; Slagter et al., 2007; Lutz et al., 2008; Chiesa et al., 2011; Vago and Silbersweig, 2012; Lippelt et al., 2014). Nevertheless, given that one of the foundations of mindfulness is to enhance compassionate thoughts, feelings, and behaviors (Dalai Lama, 1995; Wallace, 2001), another important area of interest is whether mindfulness elicits changes in the social domain. Specifically, little is known about how mindfulness is related to social cognition. In this regard, some authors have suggested that meditation and mindfulness skills could be useful tools to promote social cognition domains, although research in this field is scarce, and few studies have formally addressed such issues.

\section{Social Cognition (SC)}

Social cognition can be defined as "the mental operations that underlie social interactions, including perceiving, interpreting, and generating responses to the intentions, dispositions, and behaviors of others" (Green et al., 2008, p. 1211). It involves the capacity to understand oneself and others (Lieberman, 2007), and comprises four core domains of social cognition including (i) emotion processing, (ii) social perception, (iii) theory of mind/mental state attribution (ToM), and (iv) attributional style/bias (Pinkham et al., 2014). ToM refers to a person's capacity to attribute mental states (e.g., intentions, beliefs, desires, etc.) to both themselves and others, and to appreciate that others can have mental states that differ from their own (Corcoran et al., 1995).

Another construct that has been widely related to social cognition is empathy, which implies a knowledge of others that is more embodied than logical, and which requires the individual to maintain an awareness that the emotional response is an embodied simulation of another person's experience, not to be confused with one's own experience (Lieberman, 2007). Overall, studies have demonstrated the association between deficits across social cognition domains and psychopathology, highlighting their implications for mental health (Barbato et al., 2015; Gallagher and Varga, 2015; Lahera et al., 2015).

\section{Effects of Mindfulness Meditation (and Dispositional Mindfulness) on Social Cognition Domains}

Most of the extant empirical literature investigates the role of meditation practice and mindfulness (both state and trait) in the field of emotional processing, which is broadly defined as perceiving and using emotions, including recognition perception, understanding and managing emotions (Green et al., 2008; Pinkham et al., 2014). For example, a brief (20-min) guided mindfulness meditation exercise led to significant changes in emotional processing indicative of reduced emotional reactivity (Lin et al., 2016). The study authors reported that these effects were akin to those observed in individuals with naturally high dispositional mindfulness, suggesting that the benefits of mindfulness can be cultivated through practice. Another study showed that after a brief mindfulness induction condition (15-min recording), participants were more mindful of how they focused their attention and were able to better regulate their response to the negative images (Eddy et al., 2015). A further study showed the influence of long-term meditation practice on early emotional processing in the brain, indicating that long-term meditation practice enhances frontal top-down control over fast automatic detection of stimulus salience (Reva et al., 2015).

Additionally, there evidence in respect of the impact of mindfulness on empathy (e.g., Birnie et al., 2010; Raab, 2014; Jones et al., 2016). More specifically, increased attention has been shown to enhance empathy, together with compassion and prosocial behavior, indicating small-to-medium effects of meditation based on a systematic review and meta-analysis (Luberto et al., 2018). Furthermore, Ridderinkhof et al. (2017) investigated whether mindfulness meditation (5-min exercise) increased empathy, and they observed no effect of mindfulness relative to both control conditions (relaxation and mindwandering) on mind reading (ToM), empathic responding, or prosocial behavior. The authors also found that mindfulness meditation improved mind reading (i.e., ToM) only in nonnarcissistic people, questioning whether a brief mindfulness exercise would be sufficient for building empathy.

Another study revealed that a brief mindfulness meditation (5-min mindfulness induction) enhanced both ToM and empathic concern, compared with the control group (Tan et al., 2014). Findings from the study, together with studies suggesting linkages between ToM and mindfulness (i.e., improved executive attention, improved cognitive operations to map the minds of self and others via present-moment thinking, overlapping of cortical regions that play a role during meditation and for mindreading and self-referential mental activity; e.g., Farb et al., 2007; Siegel, 2007; Tang et al., 2009; Hölzel et al., 2011a), support the 
idea that mindfulness meditation may play a powerful role in promoting core aspects of social cognition functions.

Furthermore, Melloni et al. (2013) investigated the comprehensive effects of meditation on several domains of social cognition such as emotional recognition, empathy and ToM facets of social cognition. The results of their study indicated that meditators' performance did not differ when compared with that of non-meditators (controls), except on reported lower accuracy in disgust emotion recognition in long-term meditators and lower personal distress (empathy subscale) in both long- and short-term meditators (i.e., versus non-meditators). However, while these findings were asynchronous with extant theory and the consensual understanding of mindfulness and social cognition, the study sample only comprised 10 non-meditators, 10 long-term meditators, and 9 short-term meditators. Therefore, further research is clearly needed in order to gauge whether these outcomes are robust.

\section{Social Mindfulness}

Despite studies claiming a role for meditation and dispositional mindfulness in social cognition domains, there is a noteworthy gap in the literature with regard to how meditation and dispositional mindfulness (including mindfulness facets) are associated with specific social cognition domains - i.e., how paying attention to the experience of the present moment affects the way people see and interact with the world. Thus, there is a lack for theoretical background in order to build a solid conceptual model.

An interesting proposal is suggested by Van Doesum et al. (2013), who adopted the novel concept of social mindfulness and conducted a series of studies suggesting how social mindfulness can help people to navigate the social world based on an interdependence and decisionmaking theoretical approach. According to these authors, social mindfulness is minding the needs and interests of others in a way that honors the idea that most people like to choose for themselves. Thus, it is conceptualized in terms of other-regarding choices involving both skill (to see it, e.g., ToM, perspectivetaking) and will (to do it, e.g., empathic concern, prosocial orientation) to act mindfully toward another person's control over outcomes. Several of Van Doesum et al.'s (2013) study findings are worth highlighting: (i) people with other-oriented mindsets left interdependent others more choice than people with self-oriented and/or unspecified mindsets; (ii) people developed more favorable judgments of a socially mindful versus a socially unmindful person; (iii) unknown others with trustworthy (vs. untrustworthy) faces were met with more social mindfulness; (iv) social mindfulness could be traced in personality by being positively related to Honesty-Humility and Agreeableness, Empathy, and a prosocial value orientation. Findings from this study warrant the importance of further research on this issue, focusing on mindfulness and social cognition in order to better understand how these constructs are related.

\section{Aims of the Study}

The present authors propose that there exists a significant relationship between meditation practice, dispositional mindfulness and performance across social cognition domains. More specifically, we propose that meditation practice cultivates mindfulness skills (i.e., awareness of internal and external experiences by broadening perspective without automatically reacting) which implies a greater ability to perceive, interpret, and generate responses to the intentions, dispositions, and behaviors of others (i.e., the core of social cognition domains). A study confirming our assumptions would imply that mindfulness can be a useful technique for modifying how a person perceives the world by enhancing their performance on social cognition variables such as emotion recognition, ToM, attributional style/bias and empathy. More generally, identifying how specific facets of mindfulness relate to social cognition domains should foster a better comprehension of the social mind and behavior and, thus, help to promote wellbeing in the general population as well as improve psychological interventions focused on social cognition deficits.

Accordingly, the aim of the present study was to explore the role of meditation and dispositional mindfulness on social cognition. First, we aimed to compare the performance of meditators and non-meditators on a battery of social cognition measures. Second, we aimed to explore the relationship between dispositional mindfulness and social cognition measures. Third, we also focused on exploring whether dispositional mindfulness (and which specific facets of mindfulness) significantly predict social cognition outcomes. It was hypothesized that the meditation group would perform better on indices of social cognition performance (i.e., empathy, emotional recognition, ToM, and hostile attributional style/bias) versus non-meditators. Furthermore, it was hypothesized that dispositional mindfulness (overall score and mindfulness facets) would be associated with social cognition (empathy, emotional recognition, ToM, and attributional style) and significantly explain the variance of social cognition outcomes.

\section{MATERIALS AND METHODS}

\section{Design}

A cross-sectional two-arm design was used. The study followed Helsinki Convention norms and posterior modifications, and the Declaration of Madrid of the World Psychiatric Association. The Clinical Research Ethics Committee of Aragon approved the study protocol. Figure 1 shows the flow chart.

\section{Participants}

A total of 60 participants (meditators, $n=30$; non-meditators, $n=30$ ) were enrolled in the study. The meditation group comprised students from a Masters in Mindfulness Program at the University of Zaragoza, Spain. The non-meditation group (controls) comprised healthy volunteers from the community without meditation experience. The mean age was 42.50 $(S D=7.83)$ and ranged between 26 and 55 years (male, $n=20$; female, $n=40)$. Most participants had completed higher education $(73.3 \%)$, were in fulltime work $(73.3 \%)$, and married (60\%). Using visual inspection of demographic information, 


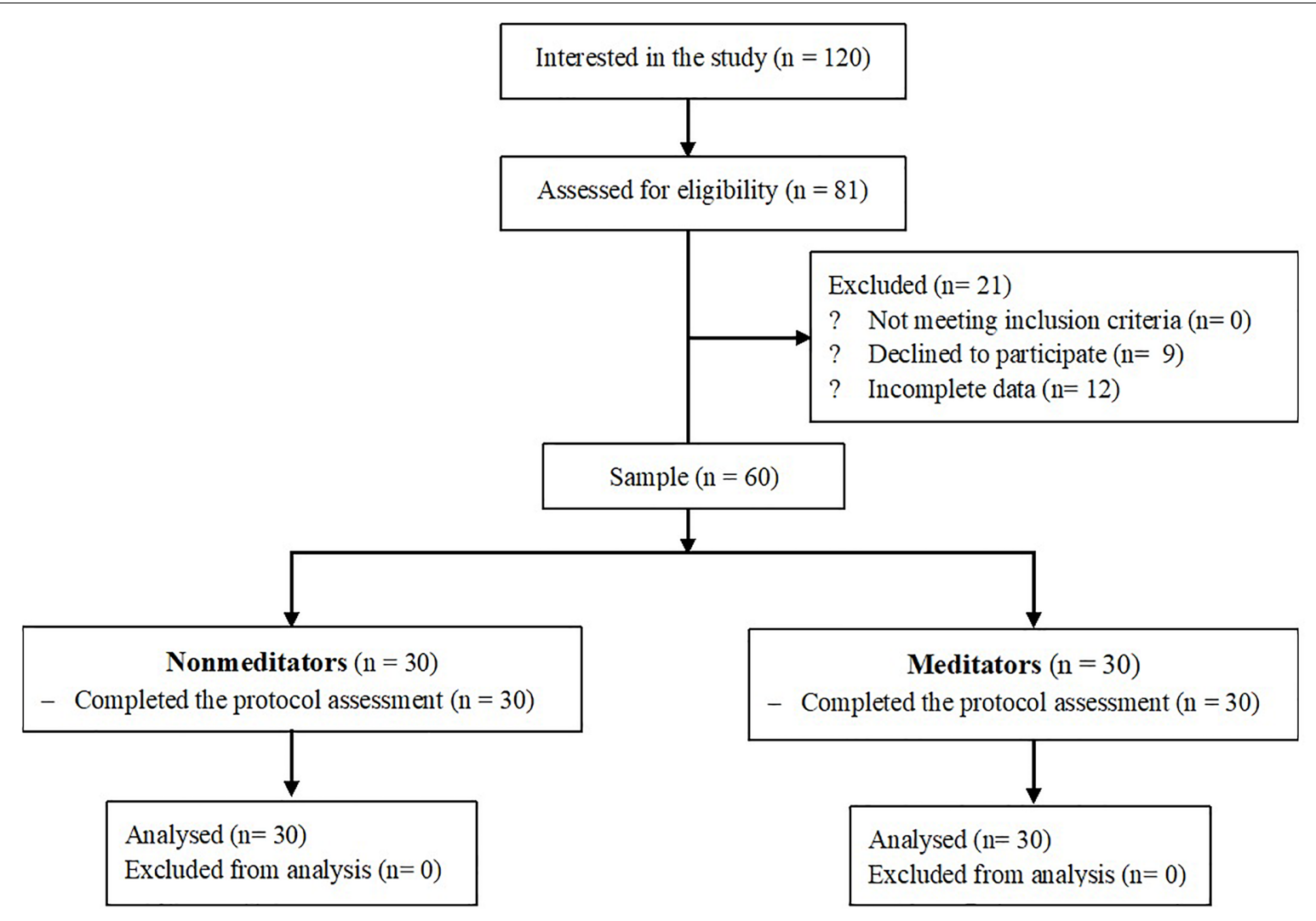

FIGURE 1 | Flow chart of the study.

the non-meditators were matched with meditators on sex, age, and ethnicity.

\section{Recruitment and Procedure}

The study was advertised on the webpage of the Masters in Mindfulness of the University of Zaragoza. To be eligible for the meditation group, participants had to have at least 1 year's meditation experience prior to the start of the study. Additional eligibility criteria (for both the meditation and non-meditation group) were (i) an age of between 18 and 65 years, (ii) ability to read and understand Spanish, and (iii) not having been diagnosed with a mental disorder or undergoing psychiatric pharmacological treatment. Participants in the meditation group were advised not to meditate for $2 \mathrm{~h}$ prior to or while undergoing the assessment. Informed consent was obtained from all participants.

\section{Measures}

\section{Socio-Demographic and Meditation Data}

Socio-demographic data were obtained for age, sex, occupation, educational attainment, and presence of a psychiatric condition or psychological disorder. Mindfulness practice data were assessed using a brief questionnaire (Soler et al., 2014a; Campos et al., 2016; Cebolla et al., 2017) containing questions relating to meditation experience (yes/no), frequency of meditation practice (every day, three or four times a week, once a week, two or three times per month, or sporadically), years of meditation experience, and the average duration of each meditation session in minutes.

\section{Dispositional Mindfulness Measures}

The Mindful Attention Awareness Scale (MAAS) is a 15-item scale that assesses the individual's dispositional capacity to be aware and conscious during every moment of the day (Brown and Ryan, 2003; Soler et al., 2012). A Spanish version of the scale - demonstrated to have good psychometric properties (Cronbach's $\alpha=0.897$ ) - was used in the current study (Soler et al., 2012). The Cronbach's alpha value for the sample in this study was 0.91 .

The Five Facet Mindfulness Questionnaire - Short form (FFMQ-SF) (Bohlmeijer et al., 2011) is a 24-item short-form version of the FFMQ (Baer et al., 2006, 2008; Cebolla et al., 2012; Aguado et al., 2015) that assesses five different facets of mindfulness: (i) observing, which refers to the individual's capacity to pay attention to internal and external experiences such as sensations, thoughts, and emotions, (ii) describing, which assesses the ability to describe events and personal responses in words, (iii) acting with awareness, which involves focusing on the activity being carried out instead of behaving automatically, (iv) non-judging of inner experience, which refers to the ability to take a non-evaluative stance toward thoughts and feelings, and (v) non-reactivity to inner experience, which involves allowing 
thoughts and feelings to come and go without getting caught up in or carried away by them (Baer et al., 2008). Both the FFMQ and FFMQ-SF, as well as the validated Spanish version, have shown to be reliable and valid instruments in adult populations. The Cronbach's alpha value for the sample in this study was 0.86 for the total score and ranged between 0.63 and 0.76 for the subscales (observe, $\alpha=0.73$; describe, $\alpha=0.63$; awareness, $\alpha=0.66$; non-judging, $\alpha=0.76$; non-reactivity, $\alpha=0.66$ ).

\section{Social Cognition Measures Empathy}

The Interpersonal Reactivity Index (IRI) (Davis, 1980, 1983) is a 28-item questionnaire scored on a Likert scale ranging between 0 ("doesn't describe me at all") and 4 ("describes me very well"). The IRI assesses four components of empathy including (i) fantasy (F) (i.e., the tendency to identify with fictitious characters), (ii) perspective-taking (PT), (iii) empathic concern (EC), and (iv) personal distress (PD) in the face of others' suffering. The IRI has been validated in Spanish with psychometric properties similar to those of the original Englishlanguage version (Pérez-Albéniz et al., 2003). For the sample in this study, the alpha value ranged between 0.52 and 0.75 for the subscales (fantasy, $\alpha=0.52$; perspective-taking, $\alpha=0.75$; empathic concern, $\alpha=0.73$; personal distress, $\alpha=0.58$ ).

\section{Emotion recognition}

The Eyes Test (revised version) is a measure comprising 36 photographs of the eye region of the faces of different actors and actresses. Respondents are asked to choose which of four words best describes what the person in the photograph is thinking or feeling (Baron-Cohen et al., 2001). The test has proven to be a sensitive measure of adult social intelligence (Baron-Cohen et al., 2001, 2015). The Spanish version, used in this study, has shown that the Eyes Test is reliable and stable over a 1-year period, in a non-clinical sample of adults (Fernández-Abascal et al., 2013). For the sample in this study, the alpha value was 0.62 .

\section{Theory of mind (ToM)}

The Hinting Task was developed to assess the ability of respondents to infer the true intention behind indirect speech utterances throughout 10 short passages reflecting an interaction between two characters (Corcoran et al., 1995). The total score range is 0-20. A detailed description of the task, instructions and correction form can be found in Corcoran et al. (1995). The Hinting Task has demonstrated good psychometric properties in the validated Spanish version (Corcoran et al., 1995; Greig et al., 2004; Gil et al., 2012). For the sample in this study, the alpha value was 0.57 .

\section{Attributional style}

The Ambiguous Intentions and Hostility Questionnaire (AIHQ) is a measure to assess hostile social-cognitive biases (Combs et al., 2007). This task is comprised of 15 short vignettes that reflect negative outcomes that vary in intentionality (i.e., intentional, accidental, and ambiguous intention). Respondents are asked to read each vignette, imagine the scenario happening to them, and to write down (i) the reason why the other person or persons acted in a particular manner (Hostility Bias, AIHQ-HB subscale), (ii) whether the other person or persons performed the action on purpose (Intentionality Bias, AIHQ-IS subscale), (iii) how angry it made them (the respondents) feel (Anger Bias, AIHQ-AS subscale), (iv) how much they would blame the other person or persons (Blame Scale, AIHQ-BS subscale), and (v) how they would respond to the situation (Aggressivity Bias, AIHQ-AB subscale). The AIHQ had good internal consistency and interrater reliability (Combs et al., 2007). For the sample in this study, the alpha values ranged between 0.81 and 0.91 for the subscales (Hostility Bias, $\alpha=0.91$; Intentionality Bias, $\alpha=0.77$; Anger Bias, $\alpha=0.86$; Blame Scale, $\alpha=0.84$; Aggressivity Bias; $\alpha=0.81$ ).

\section{Other Measures \\ Depression and anxiety}

The Hospital Anxiety and Depression Scale (HADS) (Zigmond and Snaith, 1983; Crawford et al., 2001) is a self-report tool that contains 14 items measured on a four-point Likert scale that assess anxiety and depression. The Spanish version of HADS has shown good psychometric properties for both psychiatric and healthy samples (Tejero et al., 1986; Terol et al., 2007). For the sample in this study, the alpha value was 0.79 .

\section{Cognitive impairment}

The Screen for Cognitive Impairment in Psychiatry (SCIP; Purdon, 2005) is a brief scale to assess cognitive impairment, including immediate and delayed verbal learning, working memory, verbal fluency, and psychomotor speed. The validated Spanish version of the SCIP has demonstrated properties similar to those found in the English version (Pino et al., 2006). For the sample in this study, the alpha value was 0.74 .

\section{Data Analyses}

Differences between groups regarding socio-demographic data were assessed using chi-square $\left(\chi^{2}\right)$ tests for categorical variables (sex, educational attainment, and occupation) and $t$-tests for continuous variables (age). Independent Student $t$-tests were used to assess mean differences between meditators and non-meditators on each study measure. Between-group effect sizes (Cohen's d; 95\% CI) were also calculated and reported (Cohen, 1988; Lakens, 2013; Botella and Sánchez-Meca, 2015). Separate analyses of covariance (ANCOVA) or multivariate analyses of covariance (MANCOVA) (when appropriate) controlling for socio-demographic differences (educational attainment) were added on each dependent variable (VD) in order to explore the influence of significant demographic data. Pearson correlations were conducted to explore the relationship between dispositional mindfulness and social cognition measures for the total sample, and separately for both meditator and non-meditator samples. Finally, multiple linear regressions (stepwise method) were carried out to examine the dispositional mindfulness variables that predict social cognition domains. Thus, dispositional mindfulness (assessed by MAAS), mindfulness facets, and educational attainment were entered simultaneously in order to determine which factors significantly contributed to explaining the variance in each domain of social 
cognition. All analyses were based on completers and performed using IBM SPSS Statistics 23.0 for Windows.

\section{RESULTS}

Table 1 shows the socio-demographic data for each group separately. No statistically significant differences between groups were identified in socio-demographic characteristics, except for educational attainment $\left[\mathrm{X}^{2}(2)=9.318 ; p<0.01\right]$, where the meditators group showed a higher proportion of secondary and university students. In terms of frequency of practice, $13.3 \%$ of meditators reported practicing formal meditation every day; $43.3 \%$ practiced three or four times a week; $20 \%$ practiced once a week; $6.7 \%$ practiced two or three times per month; and $16.6 \%$ meditated sporadically. The mean years of meditation experience was 3.57 $(S D=7.46)$. On average, participants meditated for $18.67 \mathrm{~min}$ $(S D=12.80)$ per session.

Means comparisons showed statistically significant differences between meditators and non-meditators for social cognition measures with effect sizes ranging between 0.60 and 1.22 (Table 2). Meditators scored significantly higher on empathy subscales: Fantasy $[t(58)=-2.35$; $p<0.05]$, perspective-taking $[t(58)=-4.773 ; p<0.001]$, and empathic concern $[t(58)=-3.739 ; p<0.001]$. No significant differences were found in the personal distress subscale. In relation to emotional recognition, meditators scored significantly higher than non-meditators, as reflected by Eyes Test scores $[t(58)=-2.370 ; p<0.05]$. Similarly, statistically significant differences were found for ToM $[t(58)=-2.495 ; p<0.05]$, where meditators demonstrated better performance in the Hinting Task versus nonmeditators. For attributional style, meditators scored statistically lower than non-meditators, revealing lower hostility bias $[t(58)=2.784 ; p<0.01]$, intentionality bias $[t(58)=4.361 ; p<0.001]$, blame $[t(58)=3.989 ; p<0.001]$, anger bias $[t(58)=4.515 ; p<0.001]$, and aggressivity bias $[t(58)=2.358 ; p<0.05]$.

With regard to Dispositional mindfulness measures, independent Student $t$-tests showed significant differences between groups on MAAS $[t(58)=-3.463 ; p<0.01]$, revealing higher scores for meditators $(M=4.31 ; S D=0.84)$ compared to non-meditators $(M=3.53 ; S D=0.91)$. For FFMQ questionnaire, results showed significant differences in all mindfulness facets (all ps < 0.05) (see Table 2).

For anxiety and depression, no statistically significant differences were observed between groups in HADS scores $[t(58)=0.656 ; p=0.651 ; d=-0.17 ; 95 \%$ CI $[-0.66,0.34]]$ [(Meditators: $M=7.03 ; S D=3.66$ ) (non-meditators: $M=7.70$; $S D=4.19)]$. In relation to cognitive impairment, meditators scored significantly lower than non-meditators on the SCIP $[t(58)=3.520 ; p<0.10 ; d=-0.90 ; 95 \%$ CI $[-1.43,-0.37]]$.

Results from ANCOVA and MANCOVA controlling by educational attainment yielded statistically significant differences between groups in: empathy subscales $[F(4,53)=5.790 ; p<0.01]$ [perspective-taking $(F(2,57)=18,326 ; p<0.001)$, and empathic concern $(F(2,57)=13,271 ; p<0.01)]$; ToM $[F(2,57)=8.597$; $p<0.01]$; attributional style $[F(5,53)=5.971 ; p<0.001]$; dispositional mindfulness (MAAS) $F(2,57)=13.215 ; p<0.01$, facets of mindfulness (FFMQ) $[F(5,57)=7.289 ; p<0.001]$; and cognitive impairment $[F(2,57)=7.973 ; p<0.01]$. The covariate, Educational attainment, was not significantly related to social cognition measures except for hostility bias $[F(1,57)=12.830$;

TABLE 1 | Socio-demographic data for each group (meditators and non-meditators).

\begin{tabular}{|c|c|c|c|}
\hline & Meditators $n=30$ & Non-meditators $n=\mathbf{3 0}$ & Statistics \\
\hline Mean (SD) [range] & 42.56 (7.5) [27-55] & $42.43(8.27)$ [26-55] & $F_{(1,59)}=0.004 p=0.948$ \\
\hline Male & 10 (33.3\%) & $10(33.3 \%)$ & $x^{2}(1)=0.00$ \\
\hline Female & 20 (66.7\%) & $20(66.7 \%)$ & $p=1.00$ \\
\hline \multicolumn{4}{|l|}{ Education, $n$ (\%) } \\
\hline Secondary & $5(16.7 \%)$ & $3(10.0 \%)$ & $p<0.01$ \\
\hline University & 25 (83.3\%) & 19 (63.3\%) & \\
\hline \multicolumn{4}{|l|}{ Marital status n (\%) } \\
\hline Single & $9(30.0 \%)$ & $8(26.7 \%)$ & $X^{2}{ }_{(6)}=5.503$ \\
\hline Married & $20(66.7 \%)$ & $16(53.3 \%)$ & $p=0.138$ \\
\hline Divorced & $0(0.0 \%)$ & $5(16.7 \%)$ & \\
\hline Employed & $6(20.0 \%)$ & $23(76.7 \%)$ & $p=0.054$ \\
\hline Retired & $0(0.0 \%)$ & $4(13.3 \%)$ & \\
\hline Disability & 14 (46.7\%) & 1 (3.3\%) & \\
\hline
\end{tabular}

SD, standard deviation. Disability refers to employees with short-term disability (sick leave) at the time that the study was conducted. 
TABLE 2 | Comparisons between meditators and non-meditators on social cognition and dispositional mindfulness measures.

\begin{tabular}{|c|c|c|c|c|}
\hline & Meditators $(n=30)$ & Non-meditators $(n=30)$ & & \\
\hline Measures & M (SD) & M (SD) & $t$ & Cohen's $d[95 \% \mathrm{Cl}]$ \\
\hline IRI_PT & $25.23(1.63)$ & $21.83(3.54)$ & $-4.773^{* * *}$ & $d=1.22[0.67,1.77]$ \\
\hline IRI_FS & 21.07 (3.93) & $18.80(3.57)$ & $-2.325^{*}$ & $d=0.60[0.08,1.11]$ \\
\hline IRI_EC & $24.47(4.35)$ & $20.63(3.55)$ & $-3.739^{* * *}$ & $d=0.95[0.42,1.49]$ \\
\hline Hinting Task & $17.53(1.46)$ & $16.03(2.96)$ & $-2.495^{*}$ & $d=0.63[0.12,1.15]$ \\
\hline \multicolumn{5}{|l|}{ AlHQ } \\
\hline $\mathrm{HB}$ & $15.43(7.50)$ & $21.97(10.44)$ & $2.784^{* *}$ & $d=-0.71[-1.23,-0.19]$ \\
\hline IS & 33.23 (9.73) & $42.63(6.69)$ & $4.361^{* * *}$ & $d=-1.11[-1.65,-0.57]$ \\
\hline AS & $31.37(8.71)$ & $40.67(7.10)$ & $4.515^{* * *}$ & $d=-1.16[-1.70,-0.61]$ \\
\hline Observing & $16.07(2.48)$ & $12.93(3.11)$ & $-4.320^{* * *}$ & $d=1.10[0.28,0.56]$ \\
\hline Describing & $16.30(2.91)$ & $14.57(2.66)$ & $-2.406^{*}$ & $d=0.61[0.09,1.13]$ \\
\hline Awareness & $13.07(3.76)$ & $15.10(3.50)$ & $2.169^{*}$ & $d=-0.55[-1.07,-0.04]$ \\
\hline Non-judgment & $10.10(3.17)$ & $12.17(3.50)$ & $2.370^{*}$ & $d=-0.61[-1.13,-0.09]$ \\
\hline Non-reactivity & $19.37(2.30)$ & $15.63(2.77)$ & $-5.679^{*}$ & $d=1.45[0.88,2.02]$ \\
\hline
\end{tabular}

M, mean; SD, standard deviation; IRI, Interpersonal Reactivity Index; FS, fantasy; PT, perspective-taking; EC, empathic concern; PD, personal distress; AlHQ, Ambiguous Intentions and Hostility Questionnaire; HB, Hostility Bias; IS, Intentionality Bias; AS, Anger Bias; BS, Blame Scale; AB, Aggressivity Bias; MAAS, Mindful Attention Awareness Scale; FFMQ, Five Facet Mindfulness Questionnaire; Cl, confidence interval. ${ }^{*} p<0.05,{ }^{* *} p<0.01,{ }^{* * *} p<0.001$.

$p<0.01]$ and aggressivity bias $[F(1,57)=11.525 ; p<0.01]$, subscales from attributional style.

Pearson correlations analyses demonstrated significant correlations between dispositional mindfulness and social cognition measures for the total sample (see Table 3). Dispositional mindfulness (overall score assessed using the MAAS) was significantly correlated with empathy (except for the PD subscale of the IRI) ( $r$-values ranging from 0.293 to 0.318$)$, ToM $(r=0.283 ; p<0.05)$ and attributional style (only on the aggressivity bias subscale, $r=-0.380$; $p<0.01$ ). For mindfulness facets (assessed via the FFMQ), observing was significantly correlated with PT $(r=0.328 ; p<0.05)$ on the IRI, and with the IS $(r=-0.385 ; p<0.01), \mathrm{AD}$ $(r=-0.510 ; p<0.01)$, BS $(r=-0.571 ; p<0.01)$, and $\mathrm{AB}$ $(r=-0.391 ; p<0.01)$ subscales of the AIHQ. Awareness was significantly correlated with ToM $(r=-0.317 ; p<0.05)$ and with attributional style [(HB, $r=330$; $p<0.01$ ), (IS, $r=0.309$; $p<0.05)$, (AS, $r=0.345 ; p<0.01)$, (BS, $r=0.368 ; p<0.01$ ), (AB, $r=0.378 ; p<0.05)$ ]. The non-judgment subscale was significantly correlated with the $\mathrm{HB}(r=0.369 ; p<0.01)$ and AS $(r=0.296 ; p<0.05)$ aspects of attributional style. For non-reactivity, the results revealed a positive significant relationship with empathy (FS, PT, and EC subscales with $r$-values between 0.290 and 0.550$)$, and $\operatorname{ToM}(r=0.419 ; p=0.01)$, as well as a negative significant correlation with attributional style (for all four AIHQ subscales, $r$-values ranged between -0.556 and -0.289 ).
Correlations between mindfulness and social cognition measures for both meditators and non-meditators are include in Table 4.

Stepwise linear regression analysis showed that the nonreactivity facet of mindfulness remained the only significant predictor of empathy $\left[\mathrm{FS},\left(\beta=0.275 ; p<0.05 ; R^{2}=0.08\right.\right.$ $\left.\Delta R^{2}=0.08\right) ; \mathrm{PT},\left(\beta=0.541 ; p<0.001 ; R^{2}=0.292 ; \Delta R^{2}=0.292\right)$; EC, $\left.\left(\beta=0.366 ; p<0.01 ; R^{2}=0.134 ; \Delta R^{2}=0.134\right)\right]$; ToM $\left(\beta=0.41 ; p=0.001 ; R^{2}=0.18 ; \Delta R^{2}=0.167\right)$; and the AIHQ-IS subscale $\left(\beta=-0.483 ; p<0.001 ; R^{2}=0.233 ; \Delta R^{2}=0.233\right)$. The PD subscale from IRI was not significantly explained by any of the predictors proposed in the model. For Emotional recognition, the only significant predictor that remained in the model was Educational attainment $\left(\beta=0.366 ; p<0.01 ; R^{2}=0.068\right.$; $\left.\Delta R^{2}=0.068\right)$ ]. In regard to attributional style, the HB subscale was significantly explained $\left(R^{2}=0.306 ; \Delta R^{2}=0.068 ; F=5.369\right.$; $p<0.05)$ by dispositional mindfulness (MAAS) $(\beta=-0.264$; $p<0.05)$, non-reactivity $(\beta=-0.301 ; p<0.05)$, and educational attainment $(\beta=0.302 ; p<0.05)$. For both AS $\left(R^{2}=0.363\right.$; $\left.\Delta R^{2}=0.056 ; F=4.885 ; p<0.05\right)$ and BS subscales $\left(R^{2}=0.411\right.$; $\left.\Delta R^{2}=0.072 ; F=6.823 ; p<0.05\right)$, the significant predictors were non-reactivity [(AS: $\beta=-0.390 ; p<0.01),(\mathrm{BS}: \beta=-0.327$; $p<0.05)$ ] and observing [(AS: $\beta=-0.288 ; p<0.05$ ), (BS: $\beta=-0.395 ; p<0.01)]$. Finally, the $\mathrm{AB}$ subscale was significantly explained $\left(R^{2}=0.262 ; \Delta R^{2}=0.107 ; F=8.128 ; p<0.01\right)$ by observing $(\beta=-0.456 ; p<0.001)$ and educational attainment $(\beta=0.333 ; p<0.01)$. 
TABLE 3 | Correlations between mindfulness and social cognition measures for total sample.

\begin{tabular}{|c|c|c|c|c|c|c|c|c|c|c|c|}
\hline & \multicolumn{4}{|c|}{ IRI } & \multirow[t]{2}{*}{ Eyes Test } & \multirow[t]{2}{*}{ HT } & \multicolumn{5}{|c|}{ AIHQ } \\
\hline & FS & PT & EC & PD & & & HB & IS & AS & BS & AB \\
\hline MAAS & $0.293^{*}$ & $0.302^{*}$ & $0.318^{*}$ & -0.229 & 0.227 & $0.283^{*}$ & $-0.380^{* *}$ & -0.145 & -0.162 & -0.201 & -0.212 \\
\hline \multicolumn{12}{|l|}{ FFMQ } \\
\hline Observing & 0.183 & $0.328^{*}$ & 0.201 & -0.174 & 0.089 & 0.210 & -0.199 & $-0.385^{* *}$ & $-0.510^{* *}$ & $-0.571^{* *}$ & $-0.391^{* *}$ \\
\hline Describing & 0.076 & 0.217 & 0.118 & -0.146 & 0.065 & 0.153 & -0.121 & -0.094 & -0.082 & -0.197 & -0.049 \\
\hline Awareness & -0.075 & -0.143 & -0.058 & -0.061 & -0.112 & $-0.317^{*}$ & $0.330^{* *}$ & 0.309* & $0.345^{* *}$ & $0.368^{* *}$ & $0.378^{*}$ \\
\hline Non-judgment & -0.135 & -0.218 & -0.091 & 0.132 & -0.004 & -0.219 & $0.369^{* *}$ & 0.138 & $0.296^{*}$ & 0.231 & 0.248 \\
\hline Non-reactivity & $0.290 *$ & $0.550^{* *}$ & $0.381^{* *}$ & -0.172 & 0.051 & $0.419^{* *}$ & $-0.373^{* *}$ & $-0.473^{* *}$ & $-0.556^{* *}$ & $-0.549^{* *}$ & $-0.289^{*}$ \\
\hline
\end{tabular}

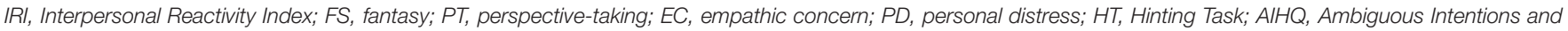

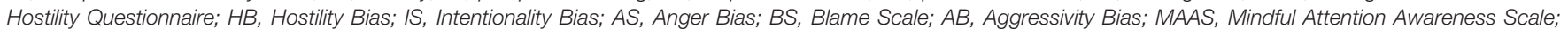
FFMQ, Five Facet Mindfulness Questionnaire. ${ }^{*} p<0.05,{ }^{* *} p<0.01$.

TABLE 4 | Correlations between mindfulness and social cognition measures for meditator and non-meditator samples.

\begin{tabular}{|c|c|c|c|c|c|c|c|c|c|c|c|}
\hline & \multicolumn{4}{|c|}{ IRI } & \multirow[t]{2}{*}{ Eyes Test } & \multirow[t]{2}{*}{ HT } & \multicolumn{5}{|c|}{ AlHQ } \\
\hline & FS & PT & EC & PD & & & HB & IS & AS & BS & AB \\
\hline \multicolumn{12}{|l|}{ Meditators } \\
\hline MAAS & 0.030 & $0.500^{* *}$ & 0.306 & -0.295 & -0.038 & 0.188 & -0.121 & 0.124 & 0.134 & 0.016 & 0.072 \\
\hline \multicolumn{12}{|l|}{ FFMQ } \\
\hline Observing & 0.141 & 0.354 & $0.378 *$ & -0.099 & 0.317 & -0.039 & 0.188 & -0.287 & -0.274 & $-0.393^{*}$ & -0.168 \\
\hline Describing & 0.253 & 0.029 & 0.122 & -0.239 & -0.139 & -0.055 & -0.173 & 0.068 & 0.156 & -0.087 & 0.235 \\
\hline Awareness & 0.194 & -0.215 & 0.015 & -0.309 & -0.144 & -0.095 & -0.088 & 0.228 & 0.294 & 0.297 & 0.184 \\
\hline Non-judgment & 0.031 & -0.310 & 0.074 & -0.151 & 0.067 & 0.057 & 0.028 & -0.071 & 0.104 & -0.065 & -0.088 \\
\hline Non-reactivity & $0.473^{* *}$ & $0.473^{* *}$ & 0.300 & 0.192 & -0.046 & 0.115 & -0.176 & $-0.362^{*}$ & $-0.377^{*}$ & $-0.419^{*}$ & -0.038 \\
\hline \multicolumn{12}{|c|}{ Non-meditators } \\
\hline MAAS & 0.159 & -0.157 & -0.021 & -0.017 & 0.236 & 0.194 & $-0.411^{*}$ & 0.005 & -0.034 & -0.057 & -0.224 \\
\hline \multicolumn{12}{|l|}{ FFMQ } \\
\hline Observing & 0.074 & -0.216 & $-0.412^{*}$ & -0.130 & -0.264 & 0.113 & -0.165 & -0.086 & $-0.431^{*}$ & $-0.552^{* *}$ & -0.360 \\
\hline Describing & -0.012 & -0.064 & -0.204 & 0.093 & 0.049 & 0.138 & 0.100 & 0.066 & -0.006 & -0.037 & -0.079 \\
\hline Awareness & -0.090 & 0.259 & 0.150 & 0.175 & 0.040 & $-0.364^{*}$ & $0.540^{* *}$ & 0.180 & 0.189 & 0.256 & $0.435^{*}$ \\
\hline Non-judgment & -0.123 & 0.191 & 0.011 & $0.388^{*}$ & 0.104 & -0.234 & $0.464^{* *}$ & 0.054 & 0.257 & 0.348 & 0.321 \\
\hline Non-reactivity & 0.309 & -0.137 & 0.031 & $-0.421^{*}$ & -0.229 & $0.385^{*}$ & -0.251 & -0.145 & $-0.366^{*}$ & $-0.376^{*}$ & -0.203 \\
\hline
\end{tabular}

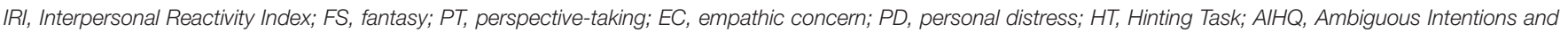

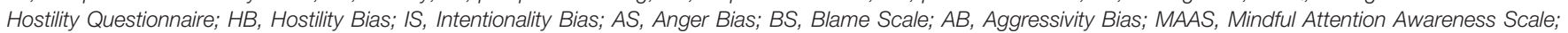
FFMQ, Five Facet Mindfulness Questionnaire. ${ }^{*} p<0.05,{ }^{*} p<0.01$.

\section{DISCUSSION}

The present study aimed to explore the role of meditation and dispositional mindfulness on social cognition. The primary aim was to investigate the difference between meditators and nonmeditators in social cognition measures. Results were in the anticipated direction and confirmed that meditators performed better on social cognition indices, compared to non-meditators. More specifically, meditators reported comparatively higher scores in empathy (expected for the personal distress aspect of empathy), emotional recognition, and ToM, and comparatively lower scores in hostile attributional style/bias. Findings from the present study are in line with established social cognitive and mindfulness theories, which assert that mindfulness fosters emotional connection to others, mental state attribution, and prosocial behavior (Hutcherson et al., 2008; Birnie et al., 2010;
Van Doesum et al., 2013; Tan et al., 2014; Lim et al., 2015). Consequently, the outcomes of this study are inconsistent with those of Melloni et al. (2013), who reported lower levels of empathy in meditators versus non-meditators. Furthermore, our findings also are contrary to Ridderinkhof et al. (2017), who found no significant effect of mindfulness mediation on empathy and mind reading (i.e., ToM).

In addition, significantly higher levels of dispositional mindfulness (assessed by MAAS) were found in meditators compared to non-meditators, which is consistent with the extensive literature supporting the use of meditation to promote mindfulness skills (e.g., Brown and Ryan, 2003; Chambers et al., 2008). In relation to mindfulness facets, meditators reported higher skills of observing, describing, and non-reactivity. However, lower levels of awareness of nonjudgment were observed compared to non-meditators. These 
findings are contrary to those expected and reported by studies indicating increased awareness and non-judgment of inner experience induced by meditation practice (Baer et al., 2006, 2008). We hypothesize that such discrepancies may be due to our sample not being limited to long-term experienced practitioners. Thus, inexperienced meditators may have reported lower levels in these outcomes due to not actually noticing that they were becoming less judgmental.

It is also important to note that when between-group comparisons were controlled by educational attainment, the results remained as they were when initially reported in all dependent variables, except for emotional recognition, where no significant differences were found between meditators and non-meditators. Although educational attainment was not a significant covariate for emotional recognition, the regression analyses revealed that it was the only significant predictor in the model. These findings may suggest the implication of educational attainment in emotional recognition, in line with studies suggesting the influence of educational attainment on the neural mechanism of facial expression processing (Demenescu et al., 2014). Moreover, educational attainment was a significant covariate for some facets of attributional style such as hostility bias and aggressivity, which may suggest the potential interference of education on these variables for our sample including both meditators and non-meditators.

A secondary objective of the study was to explore the association between dispositional mindfulness and social cognition. Findings were likewise in the hypothesized direction and are consistent with claims that mindfulness promotes adaptive social functioning (Van Doesum et al., 2013; Melen et al., 2017). More specifically, the results showed that both dispositional mindfulness and mindfulness facets were correlated-to different extents-with social cognition measures for the total sample. Dispositional mindfulness was positively correlated with empathy (except for the PD subscale) and ToM, negatively correlated with attributional style (only on the $\mathrm{AB}$ subscale), and was not significantly correlated with emotional recognition. However, no significant relationship was observed for the describing facet of mindfulness, which suggests that the ability to describe events and personal responses in words (Baer et al., 2006, 2008) is not relevant to social cognition performance. Surprisingly, the acting with awareness facet of mindfulness was negatively correlated with ToM, and positively correlated with hostile attributional style/bias. There exists evidence suggesting a link between maladaptive forms of awareness (i.e., that presumably relate to practicing aspects of mindfulness incorrectly) and psychopathology, but it is difficult to be certain whether this factor influenced outcomes in the present study (Watkins, 2004; Watkins and Teasdale, 2004; Mehling et al., 2009).

The non-reactivity facet of mindfulness showed a stronger correlation with social cognition measures in comparison with other mindfulness facets. This is consistent with mindfulness models that highlight non-reactivity as a keystone mechanism of mindfulness (Jimenez et al., 2010). Indeed, it is widely reported that meditation fosters a greater perceptual distance from internal and external cues, which in turn leads to a decentering perspective of experience along with associated reductions in emotional reactivity (Teasdale et al., 2002; Shapiro et al., 2006; Jimenez et al., 2010; Hölzel et al., 2011b; Soler et al., 2014b). According to Lutz et al. (2008), this regulatory role over attention and emotional process enhances the meditator's social performance skills. Likewise, some researchers advocate a link between meditation and emotional intelligence (Chu, 2010), and we therefore suggest that non-reactivity may play an important role in the application of emotional intelligence during social interactions (Lopes et al., 2004; Brackett et al., 2006).

In terms of the association between dispositional mindfulness and social cognition, our data also revealed different patterns of correlations when taking into account meditation practice, suggesting that dispositional mindfulness in relation to social cognition skills may be influenced by meditation practice. For example, the observing facet was significantly associated with empathetic concern in meditators but inversely so in nonmeditators, indicating that paying attention to internal and external experiences such as sensations, thoughts, and emotions decreases empathetic concern in non-meditators. These data support those studies, pointing out that observing is one of the facets most related to and influenced by meditative practice (Lilja et al., 2013; Soler et al., 2014a; Campos et al., 2016). These findings may also suggest that people with no meditation practice may have more difficulty in paying attention to their own internal and external experiences when they have empathetic concerns for others' sufferings and, therefore, become overwhelmed by the emotions of others. In contrast, for meditators, capacity to observe was associated with empathetic concern, which, according to a number of authors, increases motivation to help others in a selfless attempt to increase their wellbeing (e.g., Batson et al., 1991, 2009). Another interesting result is that dispositional mindfulness (assessed by MAAS) was significantly related to perspective-taking, which has shown to be related to empathetic response and may be an important mechanism in specific meditation practices, together with meta-awareness, cognitive reappraisal, and selfinquiry (Davis, 1983; Batson et al., 2009; Dahl et al., 2015). Contrary to our hypothesis, dispositional mindfulness was not significantly associated with ToM and emotion recognition performance in the meditator sample. Nevertheless, these data are in line with authors who did not find any significant influence of the meditation practice on mind-reading skills (e.g., Tan et al., 2014; Ridderinkhof et al., 2017), and may suggest the implication of other constructs in order to explain the relationship between meditation and both ToM and emotional recognition.

Moreover, our study showed the potential predictors that explain the variance of each social cognition variable. Overall, the non-reactivity facet of mindfulness was the only significant predictor of empathy (fantasy, perspectivetaking, and empathetic concern), ToM, and attributional style (intentionality bias). Non-reactivity also significantly predicted hostility bias (together with dispositional mindfulness and educational attainment) and both blame and anger bias (together with observing). Observing was also a significant predictor for aggressivity bias (together with educational attainment). In summary, these data highlight non-reactivity as a key facet of mindfulness in order to explain the performance in 
most of the social cognition measures, and they support the previously mentioned ideas on the importance of non-reactivity as a powerful component of mindfulness outcomes. From a pedagogical perspective, our findings suggest that specific training in mindfulness focused on observing internal and external experiences - as well as non-reactivity to such inner experience - can result in enhancement of specific social cognition domains (i.e., empathy skills, ToM, and attributional style). Future studies should investigate the mechanisms of mindfulness interventions in respect of their influence on social cognition development.

Collectively, the study findings indicate a significant relationship between dispositional mindfulness and social cognition, and suggest that mindfulness meditation plays a key role in social cognition. More specifically, based on these findings and related studies (Gallagher and Varga, 2015), we suggest the existence of a continuum on social cognition in which healthy meditators and individuals with psychopathology (i.e., schizophrenia, depression or bipolar disorder) are likely to be positioned at opposite poles and where healthy nonmeditators are likely to be positioned in the middle section. Our study partially supports this continuum as meditators performed greater on social cognition outcomes versus nonmeditators. Nevertheless, further research is needed to support these ideas and to compare differences between meditators, non-meditators and clinical samples. Despite the encouraging findings observed in this study, some limitations should be noted. First, the meditator sample comprised some individuals with only 1 year of meditation experience and, as such, the findings may not be generalizable to individuals with many years or decades of meditation experience. Second, the present study did not assess the type of meditation practiced by each meditator. As a result, the effects of the different meditation practices (e.g., focused attention, open mind, compassion) on social cognition domains were not explored. This is important because different mindfulness practices are known to work in different ways in terms of how they develop mindfulness facets and related meditative competencies (Cebolla et al., 2017). In other words, if mindfulness training were to focus on the facets that are more strongly related to social cognition, it would be reasonable to assume that it would result in a more targeted approach to improving social cognition performance. Third, despite this study employing validated measures with good psychometric properties for the Spanish version, the reliability of some measures was low $(\alpha<0.70)$ (e.g., Hinting task). Therefore, results pertaining to such measures should be interpreted with additional caution. Another limitation was that the study did not assess all measures that might be relevant to social cognition, such as compassion, self-compassion (Van Dam et al., 2011; García-Campayo et al., 2016; Elices et al., 2017), and emotional intelligence (Chu, 2010). Finally, given that this study followed a cross-sectional design (comparing meditators with non-meditators at one time-point), causal inferences are not possible. Therefore, it is not possible to definitively conclude whether mindfulness actually increases social cognition skills, or whether meditators and non-meditators simply differed in some characteristics initially. For example, perhaps people who choose to engage in mindfulness simply have higher levels of social cognition to begin with, and the reasons for practicing mindfulness meditation could therefore be related to their outcomes (e.g., see Pepping et al., 2016). Further research is needed to address these issues.

To summarize, our findings indicate that meditators perform better in certain aspects of social cognition (i.e., empathy, emotional recognition, ToM, hostile attributional style/bias) in comparison to non-meditators. Moreover, dispositional mindfulness was related to several social cognition outcomes, and mindfulness facets differently predicted social cognition performance, revealing a powerful role for non-reactivity. In the light of these findings, we hypothesize that dispositional mindfulness may enhance performance across several social cognition domains, and that such an enhancement may be promoted by meditation practice. Findings indicating a role for meditation and mindfulness in augmenting social cognition should be researched further in order to better understand this association, as well as how to modify mindfulnessbased interventions so that they maximize improvements in social cognitive performance in both clinical and nonclinical study populations. Moreover, findings from social cognition research could be useful in order to conceptualize mindfulness and meditation in a more integrative framework, in line with contemplative cognition approach proposals (e.g., Grossenbacher and Quaglia, 2017). Findings from the present study contribute to understanding the mechanisms related to how we see and navigate to the world and add exploratory data in order to develop future conceptual models explaining the role of meditation and dispositional mindfulness on social cognition domains.

\section{ETHICS STATEMENT}

All procedures performed in studies involving human participants were in accordance with the ethical standards of the institutional and/or national research committee and with the 1964 Helsinki Declaration and its later amendments or comparable ethical standards. This study was approved by the Clinical Research Ethics Committee of Aragón (Comité Ético de Investigación Clínica de Aragón, CEICA) which belongs to the Health Research Institute of Aragon (Instituto de Investigación Sanitaria de Aragón, IIS Aragón), from Zaragoza (Spain). Informed consent was obtained both informed and written by all individual participants included in the study.

\section{AUTHOR CONTRIBUTIONS}

DC analyzed the data and wrote the manuscript. MM-A and MN$\mathrm{G}$ collaborated in the writing and editing of the final manuscript. YL-d-H designed the study, and collaborated in the writing of the study and editing of the final manuscript. MG-P designed and executed the study, and collaborated in the writing and editing of the final manuscript. WVG and ES collaborated in the writing and editing of the final manuscript. JG-C designed the study, assisted with the data analyses, and collaborated in the writing and editing of the final manuscript. 


\section{FUNDING}

This project has received funding from DGA group (B1717R) and the Network for Prevention and Health Promotion in Primary Care (REDIAPP) grant from the "Instituto de

\section{REFERENCES}

Aguado, J., Luciano, J. V., Cebolla, A., Serrano-blanco, A., Soler, J., and GarcíaCampayo, J. (2015). Bifactor analysis and construct validity of the five facet mindfulness questionnaire (FFMQ) in non-clinical Spanish samples. Front. Psychol. 6:404. doi: 10.3389/fpsyg.2015.00404

Baer, R., Smith, G. T., Hopkins, J., Krietemeyer, J., and Toney, L. (2006). Using self-report assessment to explore facets of mindfulness. Assessment 13, 27-45. doi: $10.1177 / 1073191105283504$

Baer, R. A. (2003). Mindfulness training as a clinical intervention: a conceptual and empirical review. Clin. Psychol. 10, 125-143. doi: 10.1093/clipsy/bpg015

Baer, R. A., Carmody, J., and Hunsinger, M. (2012). Weekly change in mindfulness and perceived stress in a mindfulness-based stress reduction program. J. Clin. Psychol. 68, 755-765. doi: 10.1002/jclp.21865

Baer, R. A., Smith, G. T., Lykins, E., Button, D., Krietemeyer, J., Sauer, S., et al. (2008). Construct validity of the five facet mindfulness questionnaire in meditating and nonmeditating samples. Assessment 15, 329-342. doi: 10.1177/ 1073191107313003

Barbato, M., Liu, L., Cadenhead, K. S., Cannon, T. D., Cornblatt, B. A., McGlashan, T. H., et al. (2015). Theory of mind, emotion recognition and social perception in individuals at clinical high risk for psychosis: findings from the NAPLS-2 cohort. Schizophr. Res. Cogn. 2, 133-139. doi: 10.1016/j.scog.2015.04.004

Baron-Cohen, S., Bowen, D. C., Holt, R. J., Allison, C., Auyeung, B., Lombardo, M. V., et al. (2015). The "reading the mind in the eyes" test: complete absence of typical sex difference in 400 men and women with autism. PLoS One 10:e0136521. doi: 10.1371/journal.pone.0136521

Baron-Cohen, S., Wheelwright, S., Hill, J., Raste, Y., and Plumb, I. (2001). The "Reading the Mind in the Eyes" test revised version: a study with normal adults, and adults with Asperger syndrome or high-functioning autism. J. Child Psychol. Psychiatry 42, 241-251. doi: 10.1111/1469-7610.00715

Batson, C. D., Ahmad, N., and Lisner, D. A. (2009). "Empathy and altruism," in Oxford Handbook of Positive Psychology, eds C. R. Snyder and S. J. Lopez (Oxford: Oxford University Press), 417-426.

Batson, C. D., Batson, J. G., Slingsby, J. K., Harrell, K. L., Peekna, H. M., and Todd, R. M. (1991). Empathic joy and the empathy-altruism hypothesis. J. Pers. Soc. Psychol. 61, 413-426. doi: 10.1037/0022-3514.61.3.413

Birnie, K., Speca, M., and Carlson, L. E. (2010). Exploring self-compassion and empathy in the context of mindfulness-based stress reduction (MBSR). Stress Health 26, 359-371. doi: 10.1002/smi.1305

Bohlmeijer, E., ten Klooster, P. M., Fledderus, M., Veehof, M., and Baer, R. (2011). Psychometric properties of the five facet mindfulness questionnaire in depressed adults and development of a short form. Assessment 18, 308-320. doi: $10.1177 / 1073191111408231$

Botella, J., and Sánchez-Meca, J. (2015). Meta-Análisis en Ciencias Sociales y de la Salud [Meta-Analysis in Social and Health Sciences]. Madrid: Síntesis.

Brackett, M. A., Rivers, S. E., Shiffman, S., Lerner, N., and Salovey, P. (2006). Relating emotional abilities to social functioning: a comparison of self-report and performance measures of emotional intelligence. J. Pers. Soc. Psychol. 91, 780-795. doi: 10.1037/0022-3514.91.4.780

Brown, K. W., and Ryan, R. M. (2003). The benefits of being present: mindfulness and its role in psychological well-being. J. Pers. Soc. Psychol. 84, 822-848. doi: 10.1037/0022-3514.84.4.822

Campos, D., Cebolla, A., Quero, S., Bretón-López, J., Botella, C., Soler, J., et al. (2016). Meditation and happiness: mindfulness and self-compassion may mediate the meditation-happiness relationship. Pers. Individ. Dif. 93, 80-85. doi: $10.1016 /$ j.paid.2015.08.040

Carmody, J., and Baer, R. A. (2008). Relationships between mindfulness practice and levels of mindfulness, medical and psychological symptoms and well-being in a mindfulness-based stress reduction program. J. Behav. Med. 31, 23-33. doi: 10.1007/s10865-007-9130-7
Salud Carlos III" of the Spanish Ministry of Economy and Competitiveness, co-funded with European Union ERDF funds (RD16/0007/0005). The funding source had no influence on the design of the study, data collection and analysis, or the writing of the manuscript.

Cebolla, A., Campos, D., Galiana, L., Oliver, A., Tomás, J. M., Feliu-Soler, A., et al. (2017). Exploring relations among mindfulness facets and various meditation practices: do they work in different ways? Conscious. Cogn. 49, 172-180. doi: 10.1016/j.concog.2017.01.012

Cebolla, A., García-Palacios, A., Soler, J., Guillen, V., Baños, R., and Botella, C. (2012). Psychometric properties of the Spanish validation of the five facets of mindfulness questionnaire (FFMQ). Eur. J. Psychiatry 26, 118-126. doi: 10.4321/S0213-61632012000200005

Chambers, R., Lo, B. C. Y., and Allen, N. B. (2008). The impact of intensive mindfulness training on attentional control, cognitive style, and affect. Cogn. Ther. Res. 32, 303-322. doi: 10.1007/s10608-007-9119-0

Chiesa, A., Calati, R., and Serretti, A. (2011). Does mindfulness training improve cognitive abilities? A systematic review of neuropsychological findings. Clin. Psychol. Rev. 31, 449-464. doi: 10.1016/j.cpr.2010. 11.003

Chu, L. C. (2010). The benefits of meditation vis-à-vis emotional intelligence, perceived stress and negative mental health. Stress Health 26, 169-180. doi: 10.1002/smi.1289

Cohen, J. (1988). Statistical Power Analysis for the Behavioral Sciences, 2nd Edn. Hillsdale, NJ: Erlbaum.

Combs, D. R., Penn, D. L., Wicher, M., and Waldheter, E. (2007). The Ambiguous Intentions Hostility Questionnaire (AIHQ): a new measure for evaluating hostile social-cognitive biases in paranoia. Cogn. Neuropsychiatry 12, 128-143. doi: 10.1080/13546800600787854

Corcoran, R., Mercer, G., and Frith, C. D. (1995). Schizophrenia, symptomatology and social inference: investigating "theory of mind" in people with schizophrenia. Schizophr. Res. 17, 5-13. doi: 10.1016/0920-9964(95)00024-G

Crawford, J. R., Henry, J. D., Crombie, C., and Taylor, E. P. (2001). Normative data for the HADS from a large non-clinical sample. Br. J. Clin. Psychol. 40, 429-434. doi: 10.1348/014466501163904

Dahl, C. J., Lutz, A., and Davidson, R. J. (2015). Reconstructing and deconstructing the self: cognitive mechanisms in meditation practice. Trends Cogn. Sci. 19, 515-523. doi: 10.1016/j.tics.2015.07.001

Dalai Lama (1995). The World of Tibetan Buddhism: An Overview of Its Philosophy and Practice. Boston, MA: Wisdom Publications.

Davis, M. H. (1980). A multidimensional approach to individual differences in empathy. JSAS Cat. Sel. Doc. Psychol. 10:85.

Davis, M. H. (1983). Measuring individual differences in empathy: evidence for a multidimensional approach. J. Pers. Soc. Psychol. 44, 113-126. doi: 10.1037/ 0022-3514.44.1.113

Demarzo, M. M., Montero-Marin, J., Cuijpers, P., Zabaleta-del-Olmo, E., Mahtani, K. R., Vellinga, A., et al. (2015). The efficacy of mindfulness based-interventions in primary care: a meta-analytic review. Ann. Fam. Med. 13, 573-582. doi: 10.1370/afm.1863

Demenescu, L. R., Stan, A., Kortekaas, R., van der Wee, N. J., Veltman, D. J., and Aleman, A. (2014). On the connection between level of education and the neural circuitry of emotion perception. Front. Hum. Neurosci. 8:866. doi: 10.3389/fnhum.2014.00866

Eddy, M. D., Brunyé, T. T., Tower-Richardi, S., Mahoney, C. R., and Taylor, H. A. (2015). The effect of a brief mindfulness induction on processing of emotional images: an ERP study. Front. Psychol. 6:1391. doi: 10.3389/fpsyg.2015. 01391

Elices, M., Carmona, C., Pascual, J. C., Feliu-Soler, A., Martin-Blanco, A., and Soler, J. (2017). Compassion and self-compassion: construct and measurement. Mindfulness Compassion 2, 34-40. doi: 10.1016/j.mincom.2016. 11.003

Farb, N. A., Segal, Z. V., Mayberg, H., Bean, J., McKeon, D., Fatima, Z., et al. (2007). Attending to the present: mindfulness meditation reveals distinct neural modes of self-reference. Soc. Cogn. Affect. Neurosci. 2, 313-322. doi: 10.1093/ $\mathrm{scan} / \mathrm{nsm} 030$ 
Fernández-Abascal, E. G., Cabello, R., Fernández-Berrocal, P., and BaronCohen, S. (2013). Test-retest reliability of the 'Reading the Mind in the Eyes' test: a one-year follow-up study. Mol. Autism 4:33. doi: 10.1186/2040-2392-4-33

Gallagher, S., and Varga, S. (2015). Social cognition and psychopathology: a critical overview. World Psychiatry 14, 5-14. doi: 10.1002/wps.20173

García-Campayo, J., Navarro-Gil, M., and Demarzo, M. (2016). Attachment-based compassion therapy. Mindfulness Compassion 2, 68-74. doi: 10.3389/fpsyt.2017. 00307

Gil, D., Fernández-Modamio, M., Bengochea, R., and Arrieta, M. (2012). Adaptación al español de la prueba de teoría de la mente hinting task. Rev. Psiquiatr. Salud Ment. 5, 79-88. doi: 10.1016/j.rpsm.2011.11.004

Green, M. F., Penn, D. L., Bentall, R., Carpenter, W. T., Gaebel, W., Gur, R. C., et al. (2008). Social cognition in schizophrenia: an NIMH workshop on definitions, assessment, and research opportunities. Schizophr. Bull. 34, 1211-1220. doi: $10.1093 / \mathrm{schbul} / \mathrm{sbm} 145$

Greig, T. C., Nicholls, S. S., Wexler, B. E., and Bell, M. D. (2004). Test-retest stability of neuropsychological testing and individual differences in variability in schizophrenia outpatients. Psychiatry Res. 129, 241-247. doi: 10.1016/j. psychres.2004.09.006

Grossenbacher, P. G., and Quaglia, J. T. (2017). Contemplative cognition: a more integrative framework for advancing mindfulness and meditation research. Mindfulness 8, 1580-1593. doi: 10.1007/s12671-017-0730-1

Hölzel, B. K., Carmody, J., Vangel, M., Congleton, C., Yerramsetti, S. M., Gard, T., et al. (2011a). Mindfulness practice leads to increases in regional brain gray matter density. Psychiatry Res. Neuroimaging 191, 36-43. doi: 10.1016/j. pscychresns.2010.08.006

Hölzel, B. K., Lazar, S. W., Gard, T., Schuman-Olivier, Z., Vago, D. R., and Ott, U. (2011b). How does mindfulness meditation work? Proposing mechanisms of action from a conceptual and neural perspective. Perspect. Psychol. Sci. 6, 537-559. doi: 10.1177/1745691611419671

Hutcherson, C. A., Seppala, E. M., and Gross, J. J. (2008). Loving-kindness meditation increases social connectedness. Emotion 8, 720-724. doi: 10.1037/ a0013237

Jimenez, S. S., Niles, B. L., and Park, C. L. (2010). A mindfulness model of affect regulation and depressive symptoms: positive emotions, mood regulation expectancies, and self-acceptance as regulatory mechanisms. Pers. Individ. Dif. 49, 645-650. doi: 10.1016/j.paid.2010.05.041

Jones, S. M., Bodie, G. D., and Hughes, S. D. (2016). The impact of mindfulness on empathy, active listening, and perceived provisions of emotional support. Commun. Res. 1-28. doi: 10.1177/0093650215626983

Khoury, B., Lecomte, T., Fortin, G., Masse, M., Therien, P., Bouchard, V., et al. (2013). Mindfulness-based therapy: a comprehensive metaanalysis. Clin. Psychol. Rev. 33, 763-771. doi: 10.1016/j.cpr.2013. 05.005

Khoury, B., Sharma, M., Rush, S. E., and Fournier, C. (2015). Mindfulness-based stress reduction for healthy individuals: a meta-analysis. J. Psychosom. Res. 78, 519-528. doi: 10.1016/j.jpsychores.2015.03.009

Kiken, L. G., Garland, E. L., Bluth, K., Palsson, O. S., and Gaylord, S. A. (2015). From a state to a trait: trajectories of state mindfulness in meditation during intervention predict changes in trait mindfulness. Pers. Individ. Dif. 81, 41-46. doi: 10.1016/j.paid.2014.12.044

Lahera, G., Herrera, S., Reinares, M., Benito, A., Rullas, M., González-Cases, J., et al. (2015). Hostile attributions in bipolar disorder and schizophrenia contribute to poor social functioning. Acta Psychiatr. Scand. 131, 472-482. doi: 10.1111/acps. 12399

Lakens, D. (2013). Calculating and reporting effect sizes to facilitate cumulative science: a practical primer for t-tests and ANOVAs. Front. Psychol. 4:863. doi: 10.3389/fpsyg.2013.00863

Lieberman, M. D. (2007). Social cognitive neuroscience: a review of core processes. Annu. Rev. Psychol. 58, 259-289. doi: 10.1146/annurev.psych.58.110405.085654

Lilja, J. L., Lundh, L. G., Josefsson, T., and Falkenström, F. (2013). Observing as an essential facet of mindfulness: a comparison of FFMQ patterns in meditating and nonmeditating individuals. Mindfulness 4, 203-212. doi: 10.1007/s12671012-0111-8

Lim, D., Condon, P., and DeSteno, D. (2015). Mindfulness and compassion: an examination of mechanism and scalability. PLoS One 10:e0118221. doi: 10.1371/ journal.pone.0118221
Lin, Y., Fisher, M. E., Roberts, S. M., and Moser, J. S. (2016). Deconstructing the emotion regulatory properties of mindfulness: an electrophysiological investigation. Front. Hum. Neurosci. 10:451. doi: 10.3389/fnhum.2016.00451

Lippelt, D. P., Hommel, B., and Colzato, L. S. (2014). Focused attention, open monitoring and loving kindness meditation: effects on attention, conflict monitoring, and creativity - A review. Front. Psychol. 5:1083. doi: 10.3389/ fpsyg.2014.01083

Lopes, P. N., Brackett, M. A., Nezlek, J. B., Schütz, A., Sellin, I., and Salovey, P. (2004). Emotional intelligence and social interaction. Pers. Soc. Psychol. Bull. 30, 1018-1034. doi: 10.1177/0146167204264762

Luberto, C. M., Shinday, N., Song, R., Philpotts, L. L., Park, E. R., Fricchione, G. L., et al. (2018). A systematic review and meta-analysis of the effects of meditation on empathy, compassion, and prosocial behaviors. Mindfulness 9, 708-724. doi: 10.1007/s12671-017-0841-8

Lutz, A., Slagter, H. A., Dunne, J. D., and Davidson, R. J. (2008). Attention regulation and monitoring in meditation. Trends Cogn. Sci. 12, 163-169. doi: 10.1016/j.tics.2008.01.005

Mehling, W. E., Gopisetty, V., Daubenmier, J., Price, C. J., Hecht, F. M., and Stewart, A. (2009). Body awareness: construct and self-report measures. PLoS One 4:e5614. doi: 10.1371/journal.pone.0005614

Melen, S., Pepping, C. A., and O'Donovan, A. (2017). Social foundations of mindfulness: priming attachment anxiety reduces emotion regulation and mindful attention. Mindfulness 8, 136-143. doi: 10.1007/s12671-016-0587-8

Melloni, M., Sedeño, L., Couto, B., Reynoso, M., Gelormini, C., Favaloro, R., et al. (2013). Preliminary evidence about the effects of meditation on interoceptive sensitivity and social cognition. Behav. Brain Funct. 9:47. doi: 10.1186/17449081-9-47

Mira, A., Campos, D., Etchemendy, E., Baños, R. M., and Cebolla, A. (2016). Access to autobiographical memory as an emotion regulation strategy and its relation to dispositional mindfulness. Mindfulness Compassion 1, 39-44. doi: 10.1016/j.mincom.2016.09.005

Moore, A., and Malinowski, P. (2009). Meditation, mindfulness and cognitive flexibility. Conscious. Cogn. 18, 176-186. doi: 10.1016/j.concog.2008.12.008

Ospina, M. B., Bond, K., Karkhaneh, M., Tjosvold, L., Vandermeer, B., Liang, Y., et al. (2007). Meditation practices for health: state of the research. Evid. Rep. Technol. Assess. 155, 1-263.

Pepping, C. A., Walters, B., Davis, P. J., and O’Donovan, A. (2016). Why do people practice mindfulness? An investigation into reasons for practicing mindfulness meditation. Mindfulness 7, 542-547. doi: 10.1007/s12671-016-0490-3

Pérez-Albéniz, A., De Paúl, J., Etxeberría, J., Montes, M. P., and Torres, E. (2003). Adaptación de interpersonal reactivity index (IRI) al español. Psicothema 15, 267-272.

Pinkham, A. E., Penn, D. L., Green, M. F., Buck, B., Healey, K., and Harvey, P. D. (2014). The social cognition psychometric evaluation study: results of the expert survey and RAND panel. Schizophr. Bull. 40, 813-823. doi: 10.1093/schbul/ sbt081

Pino, Ó., Guilera, G., Gómez, J., Rojo, J. E., Vallejo, J., and Purdon, S. E. (2006). Escala breve para evaluar el deterioro cognitivo en pacientes psiquiátricos. Psicothema 18, 447-452.

Purdon, S. E. (2005). The Screen for Cognitive Impairment in Psychiatry (SCIP): Instructions and Three Alternate Forms. Edmonton: PNL, Inc.

Raab, K. (2014). Mindfulness, self-compassion, and empathy among health care professionals: a review of the literature. J. Health Care Chaplain. 20, 95-108. doi: $10.1080 / 08854726.2014 .913876$

Raffone, A., and Srinivasan, N. (2017). Mindfulness and cognitive functions: toward a unifying neurocognitive framework. Mindfulness 8, 1-9. doi: 10.1007/ s12671-016-0654-1

Reva, N. V., Pavlov, S. V., Korenyok, V. V., Loktev, K. V., and Aftanas, L. I. (2015). The influence of long-term meditation practice on early emotional processing in the brain: an ERP study. Zh. Vyssh. Nerv. Deiat. Im. I P Pavlova 65, 306-312.

Ridderinkhof, A., de Bruin, E. I., Brummelman, E., and Bögels, S. M. (2017). Does mindfulness meditation increase empathy? An experiment. Self Identity 16, 251-269. doi: 10.1080/15298868.2016.1269667

Salmon, P. G., Santorelli, S. F., and Kabat-Zinn, J. (1998). "Intervention elements promoting adherence to mindfulness-based stress reduction programs in the clinical behavioral medicine setting," in Handbook for Health Behavior Change, eds K. A. Riekert, J. K. Ockene, and L. Pbert (New York, NY: Springer), 239-266. 
Shapiro, S. L., Carlson, L. E., Astin, J. A., and Freedman, B. (2006). Mechanisms of mindfulness. J. Clin. Psychol. 62, 373-386. doi: 10.1002/jclp.20237

Siegel, D. J. (2007). Mindfulness training and neural integration: differentiation of distinct streams of awareness and the cultivation of well-being. Soc. Cogn. Affect. Neurosci. 2, 259-263. doi: 10.1093/scan/nsm034

Slagter, H. A., Lutz, A., Greischar, L. L., Francis, A. D., Nieuwenhuis, S., Davis, J. M., et al. (2007). Mental training affects distribution of limited brain resources. PLoS Biol. 5:e138. doi: 10.1371/journal.pbio.0050138

Soler, J., Cebolla, A., Feliu-Soler, A., Demarzo, M. M., Pascual, J. C., Baños, R., et al. (2014a). Relationship between meditative practice and selfreported mindfulness: the MINDSENS composite index. PLoS One 9:e86622. doi: 10.1371/journal.pone.0086622

Soler, J., Franquesa, A., Feliu-Soler, A., Cebolla, A., García-Campayo, J., Tejedor, R., et al. (2014b). Assessing decentering: validation, psychometric properties, and clinical usefulness of the experiences questionnaire in a Spanish sample. Behav. Ther. 45, 863-871. doi: 10.1016/j.beth.2014.05.004

Soler, J., Tejedor, R., Feliu-Soler, A., Pascual, J. C., Cebolla, A., and Soriano, J. (2012). Propiedades psicométricas de la versión española de la escala Mindful Attention Awareness Scale (MAAS). Actas Esp. Psiquiatr. 40, 18-25.

Tan, L. B. G., Lo, B. C. Y., and Macrae, C. N. (2014). Brief mindfulness meditation improves mental state attribution and empathizing. PLoS One 9:e110510. doi: 10.1371/journal.pone.0110510

Tang, Y. Y., Ma, Y., Fan, Y., Feng, H., Wang, J., Feng, S., et al. (2009). Central and autonomic nervous system interaction is altered by short-term meditation. Proc. Natl. Acad. Sci. U.S.A. 106, 8865-8870. doi: 10.1073/pnas.0904031106

Teasdale, J. D., Moore, R. G., Hayhurst, H., Pope, M., Williams, S., and Segal, Z. V. (2002). Metacognitive awareness and prevention of relapse in depression: empirical evidence. J. Consult. Clin. Psychol. 70, 275-287. doi: 10.1037/0022006X.70.2.275

Tejero, A., Guimerá, E. M., Farré, J. M., and Peri, J. M. (1986). Uso clínico del HAD (Hospital Anxiety and Depression Scale) en población psiquiátrica: un estudio de su sensibilidad, fiabilidad y validez. Rev. Psiquiatr. Fac. Med. Barc. 13, 233-238.

Terol, M. C., López-Roig, S., Rodríguez-Marín, J., Martí-Aragón, M., Pastor, M. A., and Reig, M. T. (2007). Propiedades psicométricas de la escala hospitalaria de ansiedad y depresión (had) en población española. Ansiedad Estrés 13, 163-176.

Vago, D. R., and Silbersweig, D. A. (2012). Self-awareness, self-regulation, and selftranscendence (S-ART): a framework for understanding the neurobiological mechanisms of mindfulness. Front. Hum. Neurosci. 6:296. doi: 10.3389/fnhum. 2012.00296

Van Dam, N. T., Sheppard, S. C., Forsyth, J. P., and Earleywine, M. (2011). Selfcompassion is a better predictor than mindfulness of symptom severity and quality of life in mixed anxiety and depression. J. Anxiety Disord. 25, 123-130. doi: 10.1016/j.janxdis.2010.08.011

Van Doesum, N. J., Van Lange, D. A., and Van Lange, P. A. M. (2013). Social mindfulness: skill and will to navigate the social world. J. Pers. Soc. Psychol. 105, 86-103. doi: 10.1037/a0032540

Van Gordon, W., Shonin, E., Dunn, T., Garcia-Campayo, J., and Griffiths, M. D. (2017). Meditation Awareness Training for the treatment of fibromyalgia: a randomised controlled trial. Br. J. Health Psychol. 22, 186-206. doi: 10.1111/ bjhp. 12224

Van Gordon, W., Shonin, E., Sumich, A., Sundin, E. C., and Griffiths, M. D. (2014). Meditation awareness training (MAT) for psychological well-being in a subclinical sample of university students: a controlled pilot study. Mindfulness 5, 381-391.

Wallace, B. A. (2001). Intersubjectivity in indo-tibetan buddhism. J. Conscious. Stud. 8, 209-230.

Watkins, E., and Teasdale, J. D. (2004). Adaptive and maladaptive self-focus in depression. J. Affect. Disord. 82, 1-8. doi: 10.1016/j.jad.2003.10.006

Watkins, E. D. (2004). Adaptive and maladaptive ruminative self-focus during emotional processing. Behav. Res. Ther. 42, 1037-1052. doi: 10.1016/j.brat.2004. 01.009

Zigmond, A. S., and Snaith, R. P. (1983). The hospital anxiety and depression scale. Acta Psychiatr. Scand. 67, 361-370. doi: 10.1111/j.1600-0447.1983.tb09716.x

Conflict of Interest Statement: The authors declare that the research was conducted in the absence of any commercial or financial relationships that could be construed as a potential conflict of interest.

Copyright (C) 2019 Campos, Modrego-Alarcón, López-del-Hoyo, González-Panzano, Van Gordon, Shonin, Navarro-Gil and García-Campayo. This is an open-access article distributed under the terms of the Creative Commons Attribution License (CC BY). The use, distribution or reproduction in other forums is permitted, provided the original author(s) and the copyright owner(s) are credited and that the original publication in this journal is cited, in accordance with accepted academic practice. No use, distribution or reproduction is permitted which does not comply with these terms. 